\title{
Analysis of Circular Microstrip Patch Antenna using Spherical Modal Expansion Technique
}

\author{
Rukmini $\mathrm{TS}^{1}$, Shilpa $\mathrm{J}^{1}$ \\ Department of \\ Telecommunication Engg \\ RV College of Engineering, \\ India,. Bangalore - 560059
}

\author{
Ravishankar $\mathrm{S}^{2}$ \\ K S Shushrutha ${ }^{2}$ \\ ${ }^{2}$ Dept of Electronics and \\ Communications Engg.,
}

\author{
Commander S.K. Thakur ${ }^{3}$ \\ ${ }^{3}$ Dy .Director (NRB), Ministry \\ of Defense, INDIA
}

\begin{abstract}
Microstrip antennas are finding increasing popularity by using their advantages in size, cost and conformity to supporting structure and easy of fabrication. In this paper analysis of circular patch, using Spherical modal Expansion technique (SME) and design of circular patch at $8.2 \mathrm{GHz}$ using IE3D simulator is presented. The solution provided by SME is analytical and therefore more efficient and accurate than numerical and ray tracing techniques. The properties of SME are exploited to perform a precision calculation. A sample computation on circular patch is performed to demonstrate validity of this approach and is supported by experimental results.
\end{abstract}

\section{Keywords}

SME (Spherical Modal Expansion Technique), Circular Microstrip patch, SMCC (Spherical Modal Complex Coefficient).

\section{INTRODUCTION}

In many antenna applications, patch antennas are becoming increasingly popular due to their additional advantages of small size and its compatibility with planar, microwave, millimeter integrated circuits (MIC's) and monolithic microwave integrated circuits (MMIC's). They are also capable of producing Circular polarization which finds application in space communication.

Circularly polarized antennas are extensively used to enhancing impedance and axial band width. However the edge fed circular patch antenna presents a high return loss which restricts the use of $50 \Omega$ microstrip transmission line as a feed. Commonly circular polarization schemes are used for space communication, wireless communication due to their flexibility in orientation at transmission and reception.

To analyze circular patch antenna characteristics, many analytical techniques have been proposed. A single feed Microstrip aperture with perturbations is proposed in [1], [2]. Ray optical techniques are extremely useful for analysis of large antennas like reflectors, since circular patch antennas are usually much smaller which are incapable of being analyzed using [3]. A unified Theory of diffraction (UTD) [4] is an extension of classical geometrical optics and it overcomes some of limitations by introducing a diffraction mechanism. But UTD is computationally much more efficient and is capable of predicting an infinite field.

An interesting and powerful technique for calculation of field is by Spherical Modal Expansion (SME) technique. SME expresses an arbitrary electromagnetic field as a double infinite sum of vector modes or waves, each of which are defined by two indices, one azimuth angle dependence ' $m$ ' and other polar angle dependence ' $n$ '. The infinite sum can be truncated by exploiting the properties of spherical waves and it is shown by the truncated series and is as accurate as $99.9 \%$ evaluated by representing field at an arbitrary point as an integral over the entire surface) [1], [9].
[5], [6]. SME technique is also used to solve field scattering by dielectric sphere as described in [7], [8].

The patch antenna has not been analyzed using SME in the open literature. In this paper we demonstrate the analysis of field pattern of circular patch at $8.2 \mathrm{GHz}(\mathrm{X}$ band) using SME. The numerical computation of SME for circular patch is carried out using Matlab. The design of circular patch at $8.2 \mathrm{GHz}$ is carried out using Matlab. The validity of numerical computation of SME by Matlab and simulation by IE3D simulator has been compared with experimental results.

\section{ANALYSIS}

Two independent vector functions which satisfy vector wave equation in spherical co-ord inate system $(r, \theta, \phi)$ are given in [4].

$$
\begin{aligned}
& \mathbf{M}_{\mathbf{m n}}=\nabla \times \Psi \mathbf{e}_{\mathrm{r}} \\
& \mathrm{N}_{\mathbf{m n}}=\nabla \times \mathbf{M}_{\mathbf{m n}}
\end{aligned}
$$

Where $\mathbf{M}_{\mathbf{m n}}, \mathbf{N}_{\mathbf{m n}}$ are called Spherical vector wave function (SVWF), $\psi$ is Solution of Scalar wave equation in Spherical Coordinate system and is given as

$$
\left.\Psi=\mathrm{z}_{\mathrm{n}}^{\mathrm{i}}(\mathrm{kr}) \mathrm{P}_{\mathrm{n}}^{\mathrm{m}}(\cos \theta)\right)_{\sin }^{\cos } \mathrm{m} \varphi
$$

Where $m=1, \mathbf{e}_{\mathbf{r}}$ is unit vector in radial direction, $\mathrm{k}$ is wave number, $\mathrm{P}_{\mathrm{n}}{ }^{\mathrm{m}}(\cos \theta)$ is associated Legendre function of $1^{\text {st }}$ kind, $\mathrm{i}=1,2,3,4 \mathrm{z}_{\mathrm{n}}{ }^{1}(\mathrm{kr})$ is Spherical Bessel, $\mathrm{z}_{\mathrm{n}}{ }^{2}(\mathrm{kr})$ Neuman, Hankel functions, Spherical Hankel function is defined by $\mathrm{z}_{\mathrm{n}}{ }^{3}(\mathrm{kr})=$ $\mathrm{h}_{\mathrm{n}}{ }^{1}(\mathrm{kr})$ and $\mathrm{z}_{\mathrm{n}}{ }^{4}(\mathrm{kr})=\mathrm{h}_{\mathrm{n}}{ }^{2}(\mathrm{kr})$ respectively, represent spherical waves propagating inward and outward from some finite source to destination.

On substituting equation (2) in (1a) and (1b) leads to equations (3a) and (3b)

$$
\begin{aligned}
\mathbf{M}_{\mathbf{m n}}= & -\frac{\mathrm{m}}{\sin \theta} \mathrm{z}_{\mathrm{n}}(\mathrm{kr}) \mathrm{P}_{\mathrm{n}}^{\mathrm{m}}(\cos \theta) \sin \theta \mathbf{e}_{\boldsymbol{\theta}} \\
& -\mathrm{z}_{\mathrm{n}}(\mathrm{kr}) \frac{\partial \mathrm{P}_{\mathrm{n}}^{\mathrm{m}}}{\partial \theta} \cos \varphi \mathbf{e}_{\varphi} \\
\mathbf{N}_{\mathbf{m n}}= & \frac{\mathrm{n}(\mathrm{n}+!)}{\mathrm{kr}} \mathrm{z}_{\mathrm{n}}(\mathrm{kr}) \mathrm{P}_{\mathrm{n}}^{\mathrm{m}}(\cos \theta) \cos \varphi \mathbf{e}_{\mathbf{r}} \\
+ & \frac{1}{\mathrm{kr}} \frac{\partial[\mathrm{rz} \mathrm{n}(\mathrm{kr})]}{\partial \mathrm{r}} \frac{\partial \mathrm{P}_{\mathrm{n}}^{\mathrm{m}}}{\partial \theta} \cos \varphi \mathbf{e}_{\theta} \\
- & \frac{\mathrm{m}}{\mathrm{kr} \sin \theta} \frac{\partial\left[\mathrm{z}_{\mathrm{n}}(\mathrm{kr})\right]}{\partial \mathrm{r}} \mathrm{P}_{\mathrm{n}}^{\mathrm{m}}(\cos \theta) \sin \varphi \mathbf{e}_{\varphi}
\end{aligned}
$$

Electric and magnetic fields can be represented as summation of free space modes where mode coefficients are determined by matching the fields which are known. (This known field is 


$$
\begin{aligned}
& \mathbf{E}=\sum_{\mathrm{n}=1}^{\infty} \mathrm{a}_{\mathrm{mn}} \mathbf{M}_{\mathbf{m n}}+\mathrm{b}_{\mathrm{mn}} \mathbf{N}_{\mathbf{m n}} \\
& \mathbf{H}=\sum_{\mathrm{n}=1}^{\infty} \mathrm{b}_{\mathrm{mn}} \mathbf{M}_{\mathbf{m n}}+\mathrm{a}_{\mathrm{mn}} \mathbf{N}_{\mathbf{m n}}
\end{aligned}
$$

Where ' $\mathbf{E}$ ' is electric field and ' $\mathbf{H}$ ' is magnetic field $a_{m n}, b_{m n}$ are spherical modal complex co-efficient (SMCC), $\mathbf{M}_{\mathbf{m n}}, \mathbf{N}_{\mathbf{m n}}$ are defined in equations (1) and (3), ' $m$ ' is azimuth field dependence and ' $n$ ' is polar modal dependence.

The SMCC is solved for making use of orthogonality relation of spherical vector wave functions and is given as

$$
\begin{aligned}
& \mathrm{a}_{\mathrm{mn}}= \frac{(2 \mathrm{n}+1)(\mathrm{n}-1) ! \int_{0}^{2 \pi \pi} \int_{0} \mathbf{E}_{\mathbf{c} \boldsymbol{\theta}} \cdot \mathbf{M}_{\mathbf{m n}} \mathrm{r}^{2} \sin \theta \mathrm{d} \theta \mathrm{d} \varphi}{\left.2 \pi \mathrm{n}(\mathrm{n}+1)(\mathrm{n}+1) ! \mathrm{z}_{\mathrm{n}}(\mathrm{kr})\right]^{2}} \\
& \mathrm{~b}_{\mathrm{mn}}=\frac{(2 \mathrm{n}+1)^{2}(\mathrm{n}-1) ! \int_{0}^{2 \pi} \int_{0}^{\pi} \mathbf{E}_{\mathbf{c} \boldsymbol{\theta}} \cdot \mathbf{N}_{\mathbf{m n}} \mathrm{r}^{2} \sin \theta \mathrm{d} \theta \mathrm{d} \varphi}{2 \pi \mathrm{n}(\mathrm{n}+1)(\mathrm{n}+1) ! \mathrm{c}_{\mathrm{n}}(\mathrm{kr})}
\end{aligned}
$$

where

$\mathrm{c}_{\mathrm{n}}(\mathrm{kr})=\left[(\mathrm{n}+1)\left(\mathrm{z}_{\mathrm{n}-1}(\mathrm{kr})^{2}\right)+\mathrm{n}\left(\left(\mathrm{z}_{\mathrm{n}+1}(\mathrm{kr})^{2}\right)\right]\right.$

Where $\mathbf{E}_{\mathbf{c} \boldsymbol{\theta}}$ is Electric field pattern of Circular Microstrip patch antenna as given by [1] [9]

$$
\begin{gathered}
\mathbf{E}_{\mathbf{c} \boldsymbol{\theta}}=\mathrm{jK}_{0} \mathrm{a}_{\mathrm{e}} \mathrm{V}_{0} \mathrm{e}^{-\mathrm{jk} \mathrm{k}_{0}{ }_{\left[\mathrm{J}_{02}^{\prime}\right] \mathbf{e}_{\boldsymbol{\theta}}}^{\prime}} \\
\mathrm{J}_{02}^{\prime}=\mathrm{J}_{0}\left(\mathrm{~K}_{0} \mathrm{a}_{\mathrm{e}} \sin \theta\right)-\mathrm{J}_{2}\left(\mathrm{~K}_{0} \mathrm{a}_{\mathrm{e}} \sin \theta\right)
\end{gathered}
$$

$\mathbf{J}_{\mathbf{0}}$ is $1^{\text {st }}$ order Bessel function, $\mathrm{K}_{0}=\frac{2 \pi}{\lambda}, a_{e}$ is effective circular aperture, $r$ is radial distance.

$$
\mathrm{V}_{0}=\mathrm{hE}_{0} \mathrm{~J}_{1}\left(\mathrm{Ka}_{\mathrm{e}}\right) \text { for E plane }(\varphi=0)
$$

\section{COMPUTATION}

The computation of SMCC is done using Matlab taking $\mathrm{m}=1$ and $\mathrm{n}$ varing from 1 to 25 .

The values of $a_{m n}$ and $b_{m n}$ are plotted in Fig (1a) and (1b) for $\mathrm{m}=1$ higher order of ' $n$ ' can be truncated by exploiting the properties of spherical waves is shown by [6] that truncated series is as accurate as $99.9 \%$.

Fig (1a) and (1b) are obtained by solving numerically, the equations (5a) and (5b)

The Electric field of Circular Patch Antenna using SME is evaluated by substituting equation (5a), (5b) and (3a), (3b) in equation (4a). In equation (3a), (3b) ' $r$ ' is in far field region $(\mathrm{r}=1000 \mathrm{~m})$, where order of $m=1$ and $n$ varing from 1 to 25 . The field pattern is shown below.

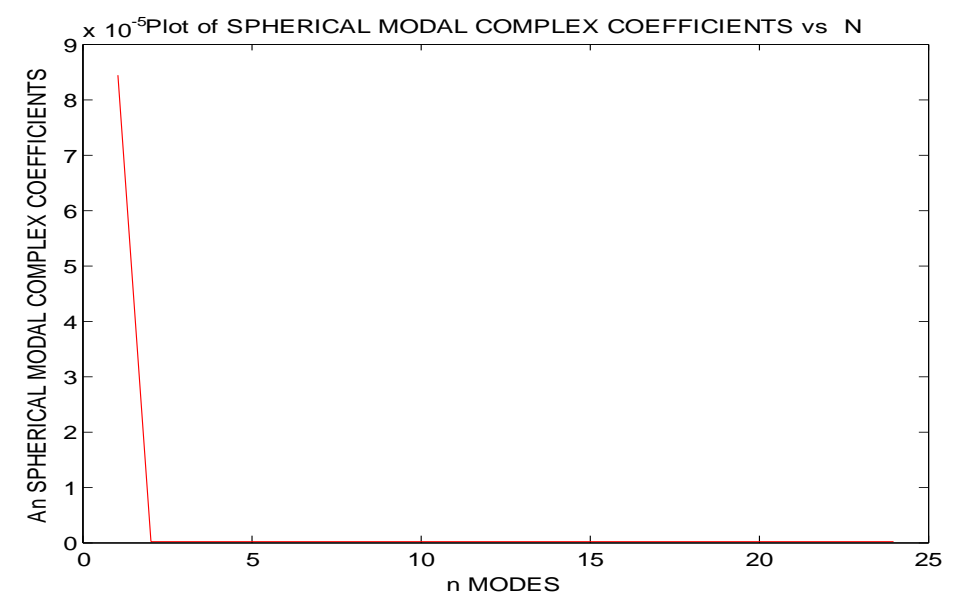

Fig 1: Spherical modal Complex Coefficient $a_{n}$ vs $n$ varying from 1 to 25

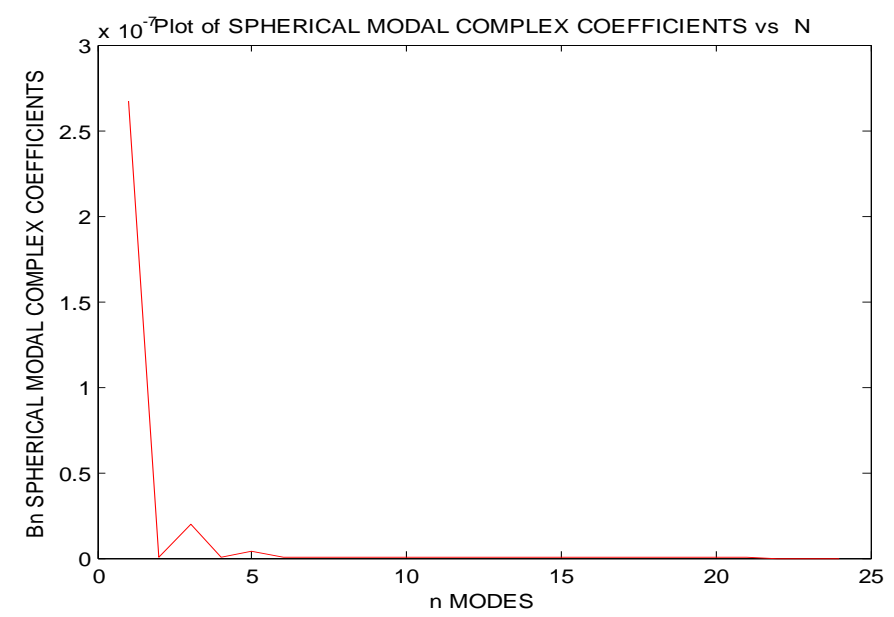

Fig. 1b. Spherical modal Complex Coefficient $b_{n}$ vs $n$ varying from 1 to 25 


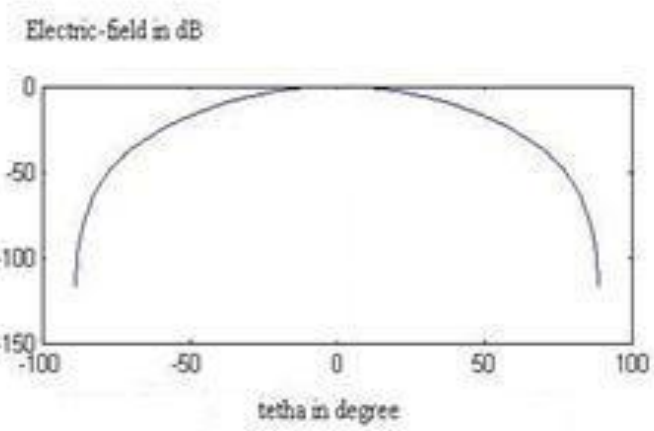

Fig. 2. Field pattern of circular patch antenna using $\mathrm{S} M E$ technique operating at 8.2GHz.

\section{DESIGN AND SIMULATION}

Circular patch is designed using field equation (6) $\mathbf{E}_{\mathbf{c} \theta}$. In the current design ground plane and substrate is assumed to be infinite for accuracy. The top view and bottom view of circular patch with feed location is given in Fig (3) and (4). The substrate RT Duriod (5880) with dielectric constant 2.3 and height of the substrate $(h)$ is $1.57 \mathrm{~mm}$, with coaxial feed is used.

To achieve circular polarization a Wilkinson power divider with two output feed lines having length difference of quarter wave which produces $90^{\circ}$ phase shift is used [11]. The proper design step is to select a suitable substrate of appropriate thickness $h$, since the bandwidth and radiation efficiency increases with substrate thickness but excess thickness is undesirable if the antenna is to have a low profile and to be conformal, for a known dielectric substrate at a specified operating frequency $f_{r}$, the radius of disk element is

$$
a=\frac{K}{\left\{1+\frac{2 h}{\Pi \varepsilon_{r} k}\left[\ln \frac{\Pi k}{2 h}+1.7726\right]\right\}^{0.5}}
$$

Where

$$
\mathrm{k}=\frac{8.794}{\mathrm{f}_{\mathrm{r}} \sqrt{\varepsilon_{\mathrm{r}}}}
$$

Where $f_{r}$ is in $\mathrm{GHz}(8.2 \mathrm{GHz})$

But the fringing effect will not occur from the above equation in the antenna. Since fringing effect makes the patch look electrically larger, a correction is introduced by using an effective radius $a_{e}$, to replace the actual radius $a$, given by

$$
a_{e}=a\left\{1+\frac{2 h}{\Pi a \varepsilon_{r}}\left[\ln \left(\frac{\Pi a}{2 h}\right)+1.7726\right]\right\}^{\frac{1}{2}}
$$

The circular patch with Wilkinson power divider is designed in IE3D simulator operating at $8.2 \mathrm{GHz}$ is as shown in Fig (5). The radiation patterns of Circular Patch obtained by simulator IE3D are shown in Fig (6) and (7). The broad side pattern is obtained. Fig (8) and (9) shows the simulated results of axial ratio $(2.5 \mathrm{~dB})$ and gain with frequency. The gain as expected is observed to be maximum at $8.2 \mathrm{GHz}$ which is the resonant frequency of the structure. Fig (10) shows the simulated results of return loss versus frequency. The return loss at 8.2 $\mathrm{GHz}$ is $-16 \mathrm{~dB}$. The photo graph of the Wilkinson power divider and fabricated structure is shown in Fig (11) and (12).

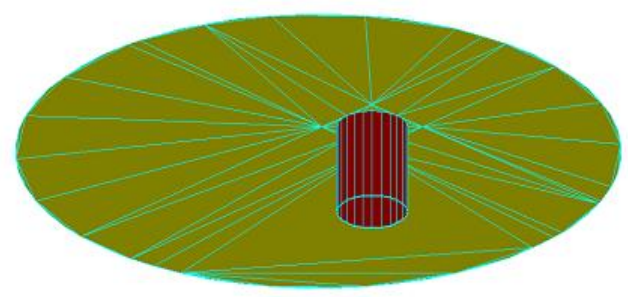

Fig.3. Shows bottom view of feed point location

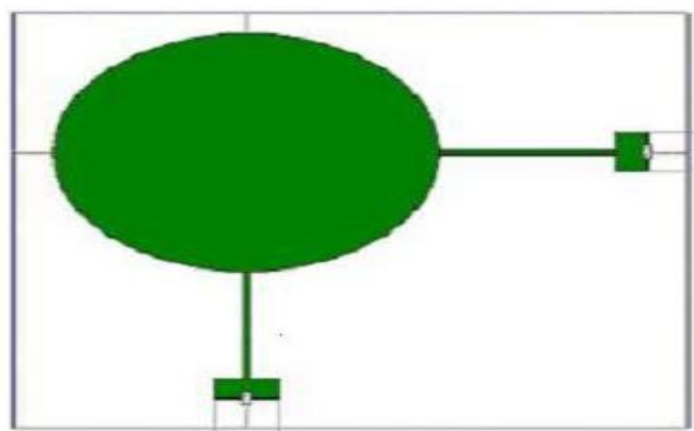

Fig. 4. Shows the top view of the feed location 


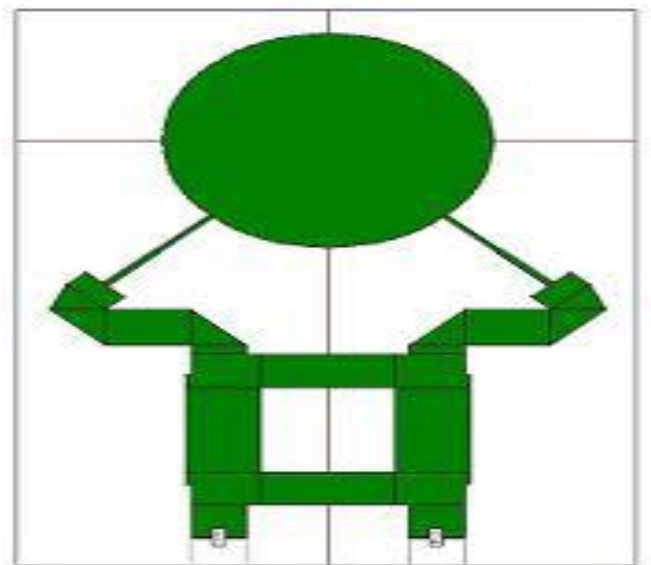

Fig. 5. Circular patch with Wilkinson power divider.
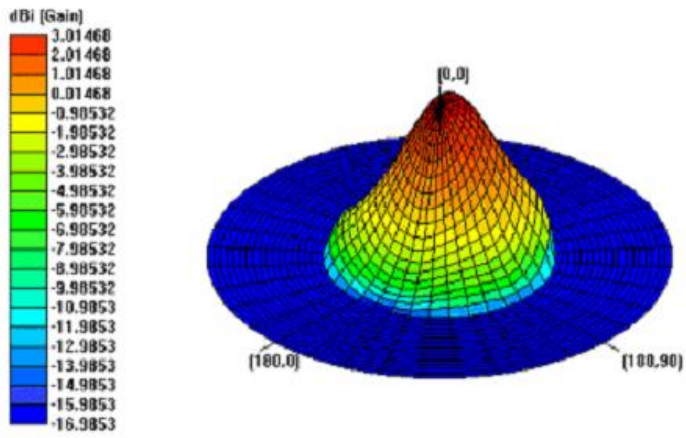

Pattem 10: Non

Freq: $8[\mathrm{GHz}$

Magnitude tar E-total
Color for dea i G ainj

Fig.6. Radiation Pattern of the simulated result using IE3D at IS RO Lab.

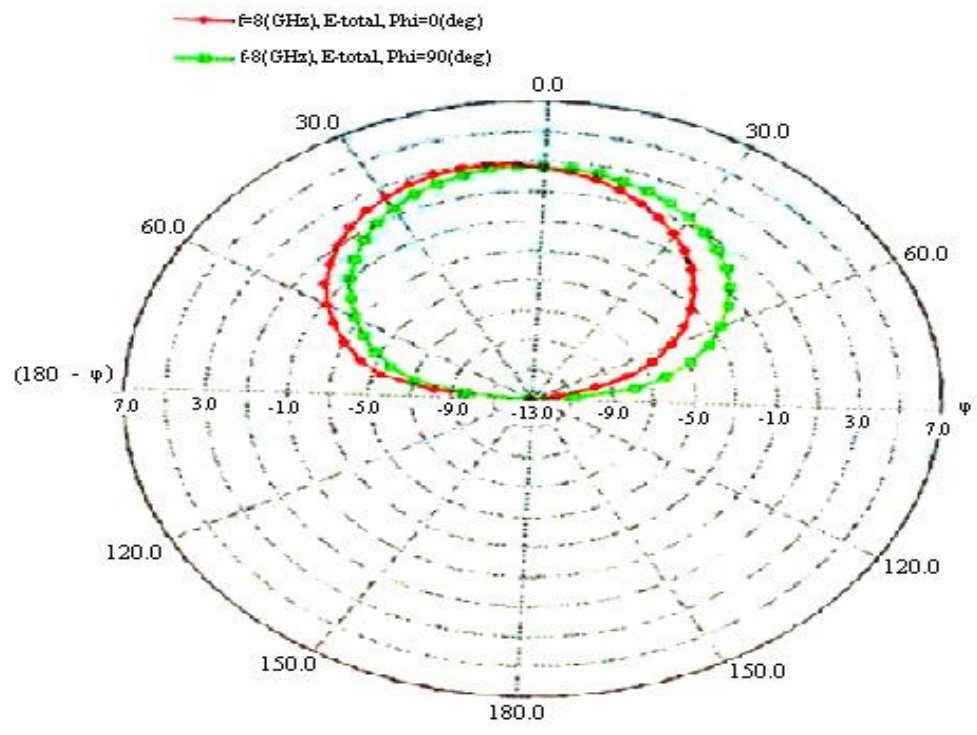

Fig.7. Two dimensional radiation patterns 


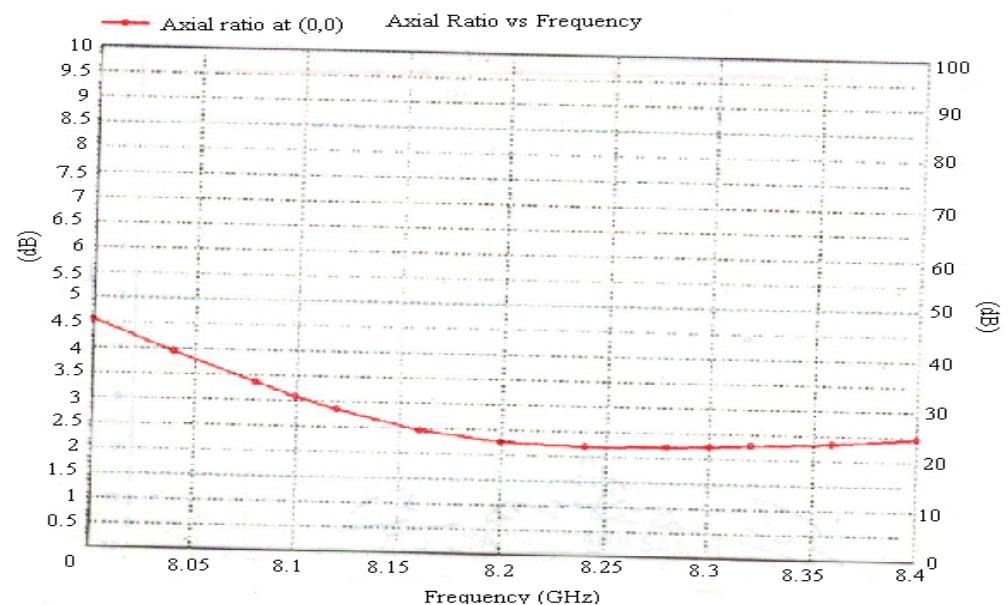

Fig. 8. Axial Ratio = 2.5dB

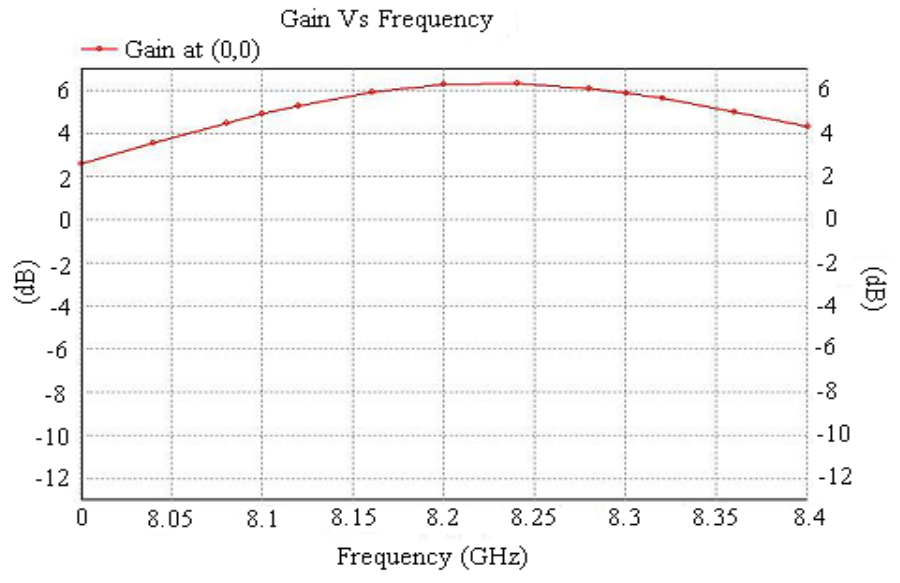

Fig.9. Shows the simulated result of gain vs. frequency. Gain $=6 \mathrm{~dB}$

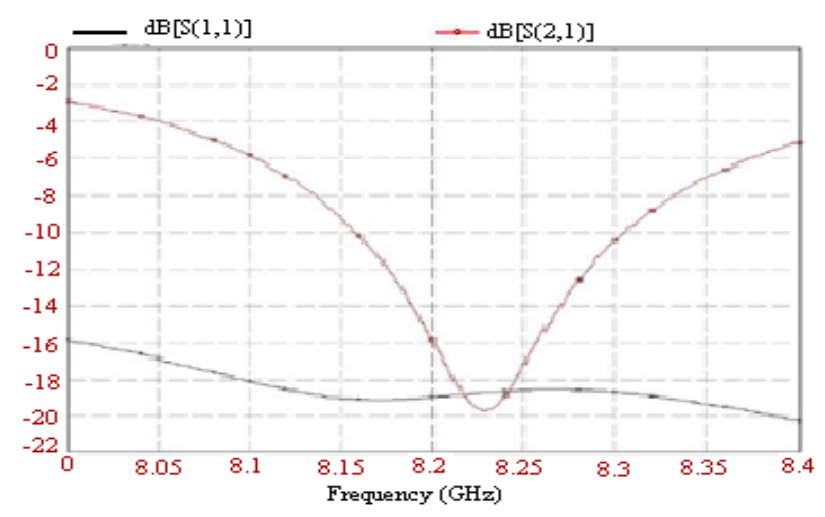

Fig.10. Shows the simulated result of Return loss vs. frequency

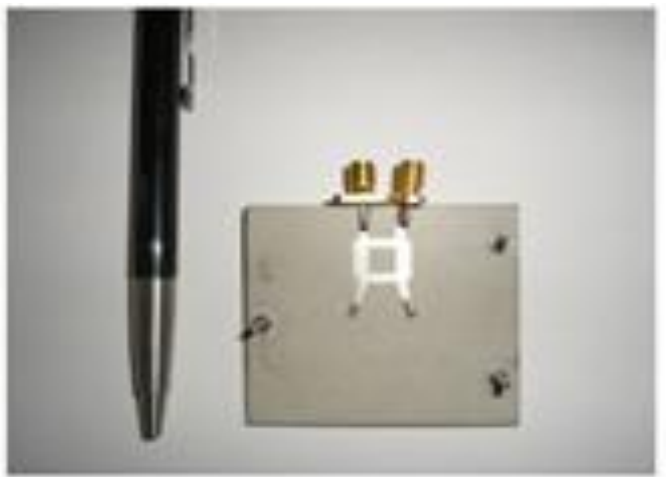

Fig.11. Wilkinson power divider 


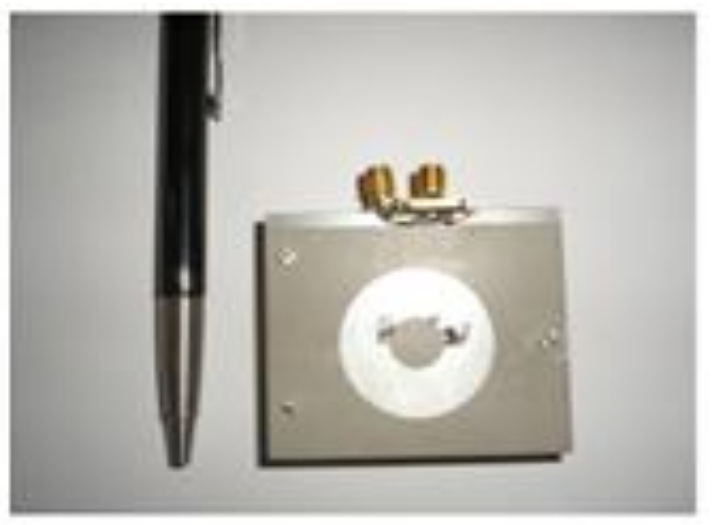

Fig 12. Circular Patch with coaxial feed

\section{EXPERIMENTAL RESULTS}

An experiment was carried out at ISRO antenna lab, and the results are presented as shown below.
At $8.2 \mathrm{GHz}, \mathrm{S}_{11}=-17.55 \mathrm{~dB}$ which are well with in our limits. The plot of $\mathrm{S}$ parameters is as shown below

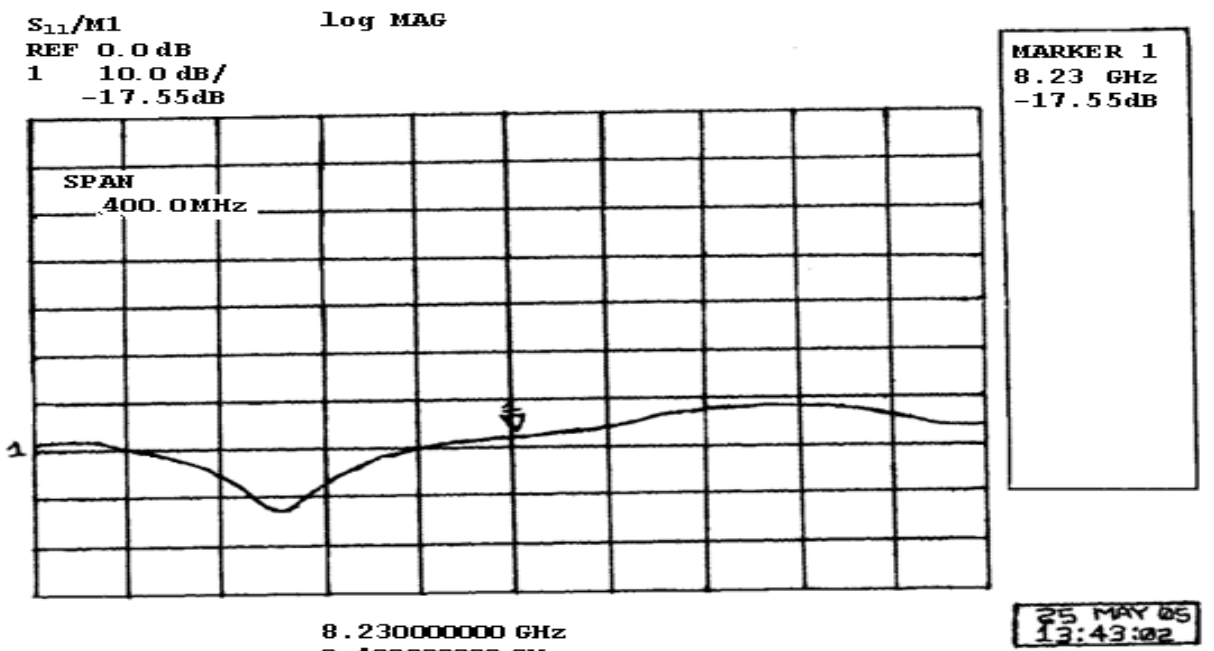

$0.400000000 \mathrm{GHz}$

Fig13. The plot of $\mathrm{S}$ parameters from $8-8.4 \mathrm{GHz}$
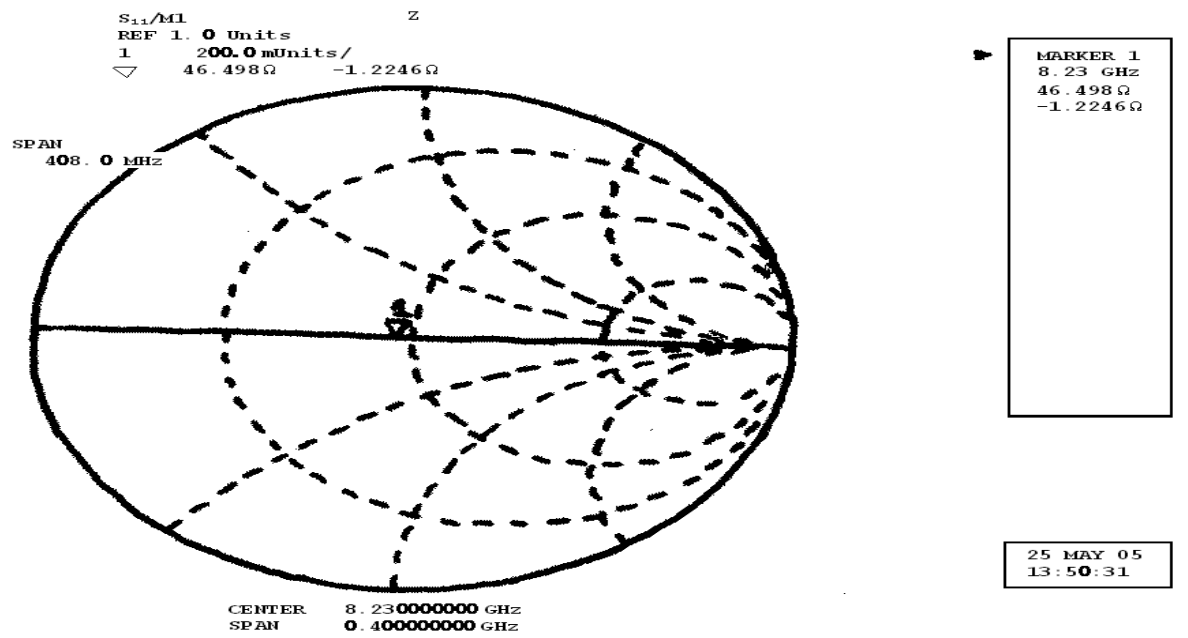

Fig14. Smith chart of Circular Patch. 
The antenna matching impedance has a resistance of $46.498 \mathrm{ohm}$ and reactance of $-1.2246 \mathrm{ohm}$ which is shown in Fig (14).
The radiation pattern of Circular patch antenna is shown below which is a broad side pattern as expected.

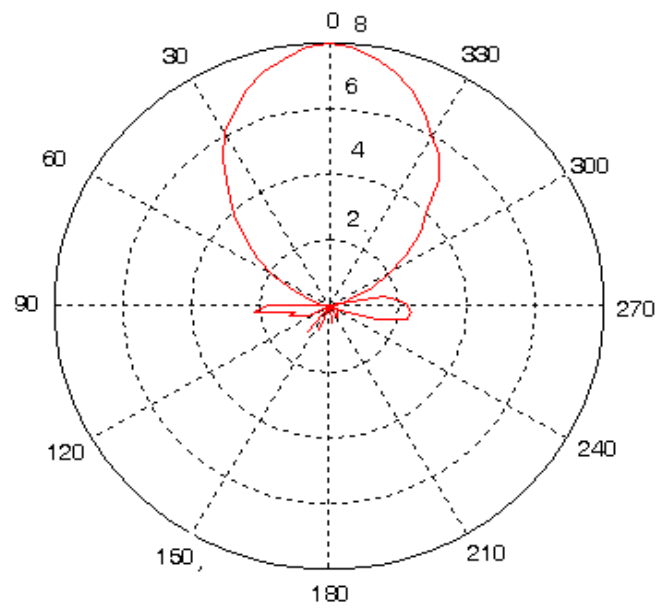

Fig15. Experimental results of radiation pattern obtained in anechoic chamber.

\section{DISCUSSION}

As it is evident from above comparison there is close agreement between SME approach, simulated results and experimental results. Some slight deviations in simulation and experimental results are due to the assumption of infinite ground plane in simulation. It is also evident that SME can further be extended to larger antenna apertures and small antennas. SME can also solve scattering problem.

The Broad side pattern obtained by SMCC agrees very well with simulated and experimental pattern and the matching impedance at resonance where the resistive part appears to be $46.498 \mathrm{ohm}$ and reactance of $-1.2246 \mathrm{ohm}$. The axial ratio and $\mathrm{S}$ parameters obtained agrees with the simulated results well with in the limits. These results prove the validity of SME.

\section{CONCLUSION}

The results obtained shows that there is a very good agrrement in pattern for both SME and simulation by IE3D amd Experimental resutls. The results are encouraging so that other patches can be tried by the same technique. Matlab evaluation has been for SME coefficients by taking twenty five values. The truncation to 25 values has been found to be very satisfactory.

\section{ACKNOWLEDGMENTS}

The Authors are grateful to Principal R.V.College of Engineering, Bangalore for his constant encouragement through out the work. Authors are also grateful to Naval Research Board (NRB), for providing fin ancial support for the project.

\section{REFERENCES}

[1] J.R.James and P.S.Halls, Eds., Handbook of Microstrip antennas. London, UK; Peter peregrines, 1989, ch 1.
[2] Y.Suzuki, N.Miy ano and T.Chiba, " Circularly polarized radiation from single fed equilateral trian gu lar Microstrip antenna," Inst.Elect.Engg, Vol 134, pt .H, pp. 194 - 198, Apr.1987

[3] Des champs G.A "Ray technique in electromagnetic", IEEE proc vol 60, 1972, pg 1022-1031.

[4] Kouyoumjian R.G. and Pathak P.H, "A uniform theory of diffraction for an edge in perfectly conducting surface", IEEE proc vol. 62, 1974 pg 1448-1461.

[5] Arther. C Ludwig Numerical check on accuracy of spherical wave expansion Electronic letter, 1972 vol. 8, pg.202-203.

[6] Potter, P.D., "Application of Spherical Wave Theory om Cassegrain-fed Paraboloids", IEEE Trans. On Ant. And Prop., Vol. AP-15, November 1967, pp. 727-736.

[7] Carlos A Fernandez "Shaped dielectric lenses for Wireless Millimeter-Wave Communications," IEEE Ant and Propag Magazine, vol 41, No 5, pp 141-150, October 1999.

[8] Ravishankar Sankaranarayanan, Mahesh Appajappa, Rukmini T S, Arjun Ravishankar, "Spherical Modal Analysis of a Patch Array Dielectric Lens Antenna”. 4th European Conference on Antennas and Propagation (EuCAP), Barcelona, Spain, on 12-16 April 2010.

[9] Constantine A Balanis, Antenna Theory - Analysis and Design, 3rd Edn, Singapore: John Wiley and Sons:

[10] Julius Adams Stratton, Electromagnetic Theory, New York, McGraw Hill Book Company, Chapter 7, 1941.

[11] Bharati Batt and S. K. Koul, Stripline-like Transmission Lines for Microwave Integrated Circuits, Wiley Eastern Ltd., (India) and John Wiley (U.S.A), 1989 